\title{
Synthesis, characterization and photocatalytic reactions of phosphated mesoporous titania
}

\author{
PALLABI GOSWAMI and JATINDRA NATH GANGULI* \\ Department of Chemistry, Gauhati University, Guwahati 781 014, India
}

MS received 7 December 2011; revised 3 January 2012

\begin{abstract}
Mesoporous titania nanoparticles with a well-defined mesostructure was prepared by hydrothermal process, using nonionic triblock copolymer P123 as surfactant template, modified with phosphoric acid and followed by calcination at $600^{\circ} \mathrm{C}$. The sol-gel titania was modified by in situ phosphorylation using phosphoric acid and thereby incorporating phosphorous directly into the framework of $\mathrm{TiO}_{2}$. The resulting materials were characterized by XRD, SEM, TEM, nitrogen adsorption, TGA and DRS. It was found that the structural and optical properties of titania samples are strongly influenced by their phosphate modification. In case of calcined samples a positive effect on the specific surface area for the in situ phosphated sample was found. Mesoporous structure of phosphated titania did not collapse even after calcination at $600^{\circ} \mathrm{C}$. The enhanced photocatalytic activity of the synthesized phosphate nanomaterials were evaluated through a study of the decomposition of fluorescein under UV light excitation and compared with undoped titania nanomaterial as well as with commercial titania.
\end{abstract}

Keywords. Phosphated titania; photocatalyst; fluorescein.

\section{Introduction}

Titanium dioxide is one of the most extensively investigated photocatalyst and is the subject of extensive research since late 1960s, due to its wide applications in various areas such as gas sensing, photocatalysis, photo electrodes for photo splitting of water, and solar energy conversion (Armstrong et al 2005). The electronic structure of $\mathrm{TiO}_{2}$ is well understood, both theoretically as well as experimentally. It is characterized by a bandgap of $3.2 \mathrm{eV}$. But unfortunately the wide application of $\mathrm{TiO}_{2}$ as a photocatalyst is limited by its UV- or near UV-absorption properties. Several methods have been reported to improve the photocatalytic efficiency of titania, which includes increasing the surface area, doping of $\mathrm{TiO}_{2}$ with different elements such as $\mathrm{N}, \mathrm{P}$ and $\mathrm{S}$, which has shown promising results for visible light photocatalysis, where visible light absorption has been achieved, generation of defect site etc. Attempts have been made to improve the photoactivity of titania both in the visible and UV range. The methods used usually include various surface modifications. Several studies were devoted to anionic modifications of $\mathrm{TiO}_{2}$, among which halogenide ions received special attention. The phosphate modification of titania has been the subject of a considerably smaller number of studies, whose results are highly diverse from a photocatalytic point-of-view. The latter is probably due to differences in preparation techniques and different phosphate contents. Colón et al (2006) used different oxoacids (nitric, sulphuric and phosphoric

\footnotetext{
*Author for correspondence (jatin_ganguli_gu@yahoo.co.in)
}

acid) for modifying $\mathrm{TiO}_{2}$. They found that the photoactivity strongly decreased after phosphoric acid treatment. The poor photocatalytic behaviour is determined by the appearance of pyrophosphate-like species at the surface. In contrast, $\mathrm{Yu}$ et al (2003) found that photocatalytic activity of $\mathrm{TiO}_{2}$ increased because of phosphate modification. The effect was explained by the increased bandgap energy, large surface area and the existence of Ti ions in tetrahedral coordination. In recent years, innovative solid catalysts have been prepared using $\mathrm{TiO}_{2}$ as supports, modified with anions such as $\mathrm{SO}_{4}^{2-}$, $\mathrm{WO}_{4}^{2-}, \mathrm{PO}_{4}^{3-}$ etc (Hino and Arata 1980; Larsen et al 1996) to improve their physicochemical properties (including thermal stability and mesoporosity). Out of three different states of titania viz. amorphous, crystalline and mesoporous, mesoporous titania is the most photocatalytically active photocatalyst because it has a high surface to volume ratio and offers more active sites for carrying out catalytic reactions. But to prepare mesostructure we often have to use surfactants as template and pore forming agent. Then after formation of the catalyst we have to calcine it at high temperature in order to remove excess surfactants. This often leads to collapse of mesoporous framework and loss of surface area due to facile crystallization of $\mathrm{TiO}_{2}$ and subsequent growth.

It was reported that the thermal stability and acidity of mesoporous materials could be greatly improved through post-treatment with phosphoric acid (Clesla et al 1996; Chen et al 2001). It has been reported that post-treatment with $\mathrm{H}_{3} \mathrm{PO}_{4}$ improves the stability of mesoporous Al-MCM-41 and zirconia. It is well known that a large amount of uncondensed Ti-OH exists on the surface of the as prepared 
amorphous titania. During calcinations, the rapid reactions between the uncondensed $\mathrm{Ti}-\mathrm{OH}$ would cause the walls of the mesoporous titania to collapse. If uniform surface treatment can be carried out with phosphoric acid then the mesostructure in titania can be retained. Because complete crosslinking in $\mathrm{TiO}_{2}$ structure occurs due to the probable reaction of uncondensed surface hydroxyl groups with phosphate ions. Moreover, $\mathrm{H}_{3} \mathrm{PO}_{4}$ can be polymerized to polyphosphoric acid with network structure at high temperatures. This network structure, which is tightly attached to the surface of mesoporous materials, can effectively resist the shrinkage of pore channels during thermal or hydrothermal treatment (Huang and Li 1999).

In this paper, we report the preparation and characterization of mesoporous titania nanomaterials by precisely controlling the process of sol-gel formation, and then modification of the synthesized gel with phosphoric acid. Also we show that incorporation of phosphorous from $\mathrm{H}_{3} \mathrm{PO}_{4}$ can stabilize the framework of mesoporous titania to produce phosphated mesoporous titania with small crystallite size, high surface area and very high thermal stability. The resulting mesoporous phosphated $\mathrm{TiO}_{2}(R 1)$ showed very high photocatalytic activity on the decomposition of fluorosceine in air and it was found that photocatalytic activity of $R 1$ was even better than that of pure mesoporous $\mathrm{TiO}_{2}(R 2)$ synthesized by same procedure.

\section{Experimental}

\subsection{Catalyst preparation}

Nano sized mesoporous phosphated titanium dioxide particles were prepared as follows. Three grams of triblock copolymer poly (ethylene glycol)-block-poly (propylene glycol)-block poly (ethylene glycol) $\mathrm{PO}_{20} \mathrm{EO}_{70} \mathrm{PO}_{20}$ (mol. wt 5800, Aldrich) and $0.03 \mathrm{~mol}$ of titanium isopropoxide $(98 \%$, ACROS) were dissolved in $30 \mathrm{ml}$ of absolute ethanol. After the solution was vigorously stirred for $2 \mathrm{~h}$, $0.003 \mathrm{~mol}$ of $\mathrm{H}_{3} \mathrm{PO}_{4}$ (85\% Merck) was added into the solution. Then the solution was sonicated for $15 \mathrm{~min}$. The resulting suspension was stirred for $1 \mathrm{~h}$ followed by addition of $50 \mathrm{ml}$ of deionized water. Again the mixture was sonicated for $15 \mathrm{~min}$. The yellow powder was obtained after slow thorough evaporation of water and ethanol. The as prepared samples were calcined at $600^{\circ} \mathrm{C}$ for $5 \mathrm{~h}$ with a heating rate of $5^{\circ} \mathrm{C} / \mathrm{min}$, and labeled as $R 1$. Pure mesoporous $\mathrm{TiO}_{2}$ was also prepared without the addition of $\mathrm{H}_{3} \mathrm{PO}_{4}$ reference and marked as $R 2$. Photocatalytic properties were compared with commercial titania powder from Merck.

\subsection{Characterization}

$\mathrm{X}$-ray diffraction patterns of the samples were recorded at room temperature with $\mathrm{Cu} \mathrm{K} \alpha$, using a Philips Analytical Diffractometer. Diffraction intensity was measured in the $2 \theta$ range between $20^{\circ}$ and $90^{\circ}$, with peak positions defined by minimum of second derivatives. The Scherrer crystallite sizes were determined using the formula

$$
D=0 \cdot 9 \lambda / \beta \cos \theta
$$

where $\lambda$ is the wavelength characteristic of the $\mathrm{Cu} \mathrm{K} \alpha$ radiation, $\beta$ the full width at half maximum (in radians) and $\theta$ the angle at which 100 intensity peak appears. Characterization of the surfaces was carried out using infrared spectroscopy, thermogravimetric analysis and surface area analyser. Nitrogen adsorption isotherms were obtained for the samples with Micromeritics Tristar 3000 Surface Area and Porosity Analyser. The surface areas were calculated using BET equation and the mean pore size diameter was calculated using the BJH method. The percentage weight loss of photocatalyst was estimated by thermogravimetric analysis (TGA) on METTLER TOLEDO TGA/DSC-1. The adsorption edges were determined from the onset of diffuse reflectance spectra of the samples measured using HITACHI, UV-VISIBLE u-4100 spectrophotometer. The bandgap of the samples was determined by the $E_{\mathrm{g}}=1,239 \cdot 8 / \lambda$ (Regan and Gratzel 1999), where $E_{\mathrm{g}}$ the bandgap energy $(\mathrm{eV})$ and $\lambda(\mathrm{nm})$ the wavelength of absorption edges in the spectra. SEM images of the mesoporous samples were recorded using a variable pressure Digital Scanning Electron Microscope (Model JSM 6380 LA). FTIR was determined with a PERKIN ELMER Spectrum RXIFT-112 spectrometer. The annealed samples were pressed into thin self-supported wafers and then IR spectra were recorded. TEM was recorded using a JEM2100, Jeol electron microscope. The type of acid sites (Bronsted and/or Lewis) was determined with a PERKIN ELMER Spectrum RXIFT-112 spectrometer by means of ammonia adsorption. The annealed samples were pressed into thin self-supported wafers. The wafers were then placed in a vacuum desiccator. The ammonia adsorption was carried out in the desiccators by placing a Petri dish containing ammonia in it. Ammonia desorption was subsequently investigated at room temperature and the corresponding spectra recorded.

\subsection{Photocatalytic activity of catalysts in aqueous phase degradation of fluoresceine}

For experiments under UV light, the desired fluorescein dye solution was prepared in double distilled water. An immersion well photochemical reactor (HEBER) made of Pyrex glass was used in this study. Irradiations were carried out using a $25 \mathrm{~W}, 254 \mathrm{~nm}$ medium pressure mercury lamp. IR radiation and short wavelength UV radiation were eliminated by a water circulating Pyrex glass jacket. The fluorescein dye solution $\left(10^{-5} \mathrm{M}\right)$ was poured into the Pyrex vessel of the photoreactor. Aqueous dispersions of the catalyst were prepared by addition of a given weight $(0.2 \mathrm{~g})$ of catalyst to about $50 \mathrm{ml}$ of aqueous solution of the dye and sonicated it 
in a sonicator for $5 \mathrm{~min}$. The dispersion was then put into the Pyrex vessel of the photoreactor along with an additional amount of the dye solution $\left(10^{-5} \mathrm{M}\right)$ just enough to fill the vessel. The dispersions were kept under constant air bubbling with the help of air pump during irradiation. At intervals of $10 \mathrm{~min}, 10 \mathrm{ml}$ aliquots of reaction mixture were withdrawn and were analysed by recording variations of absorption band maximum (500.5 $\mathrm{nm}$ for fluorescein) in a UV-Visible spectrometer. The rate of decomposition of the dye can thus be determined from the absorption vs time plots.

\section{Results and discussion}

The effect of in situ phosphorylation on the crystal size and phase structure was investigated by performing XRD analysis. The XRD patterns for all the samples calcined at $600^{\circ} \mathrm{C}$ are given in figure $1 \mathrm{a}$, indicating that the phosphate modified nanomaterials and untreated sample consist of anatase phase. The X-ray powder diffraction (XRD) patterns of the sample give characteristic peak at $2 \theta$ values $25 \cdot 5^{\circ}$ (101), $38^{\circ}$ (004), $48 \cdot 1^{\circ}(200)$ and $54 \cdot 3^{\circ}(105)$. A comparison with JCPDS data (84-1286) also confirms that both $R 1$ and $R 2$ consist of only anatase phase. For $R 1$, the main (101) anatase
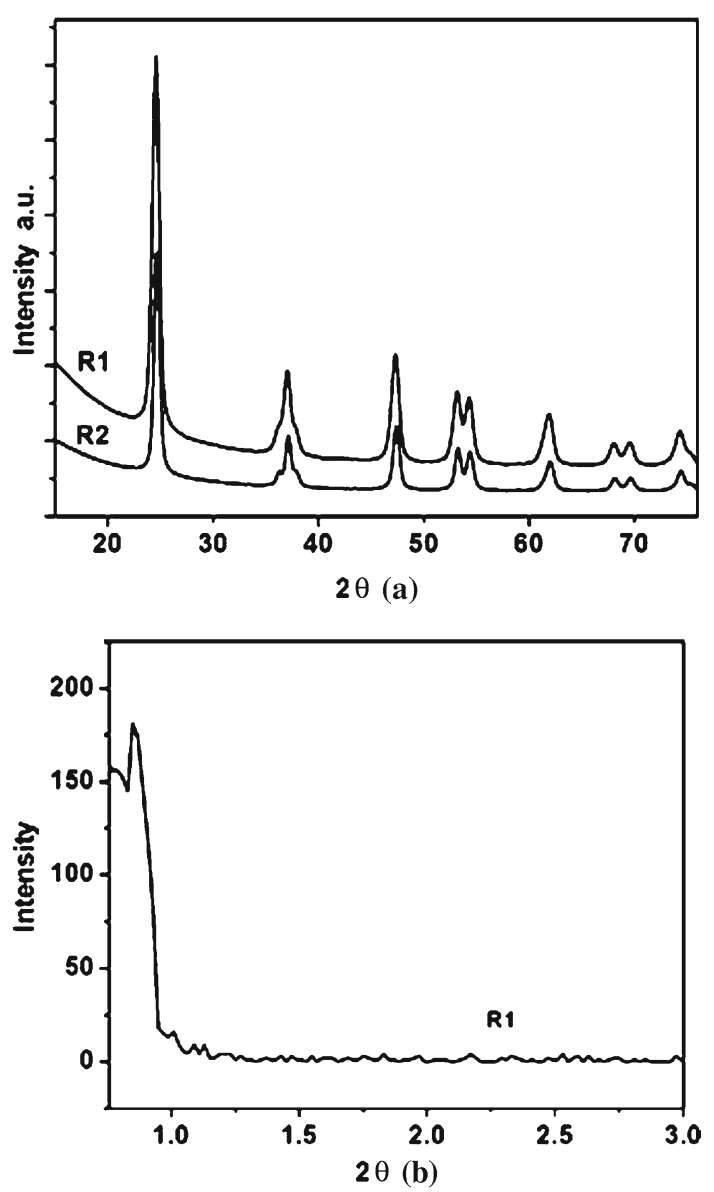

Figure 1. (a) XRD of $R 1$ and $R 2$ and (b) low angle XRD of $R 1$. peak shifts to lower 2-theta values, resulting in a decrease in particle size and an increase in the $d$ spacing. From the intensity distribution of the X-ray diffraction signals and their integral intensity, the average nanocrystallite size was calculated according to the Debye-Scherrer equation. The crystallite sizes decrease with treatment with phosphoric acid composition, i.e. for pure $\mathrm{TiO}_{2}$, crystallites were $\sim 14 \mathrm{~nm}$ whereas for phosphated crystallites it was $\sim 9.8 \mathrm{~nm}$. Compared to the $\sim 30 \mathrm{~nm}$ average diameter of a commercial titania sample, the average grain size of the phosphated $\mathrm{TiO}_{2}$ and that of undoped titania is in the range $\sim 9-14 \mathrm{~nm}$. The diffraction peaks of the nano-sized $\mathrm{TiO}_{2}$ are broad and some peaks coalesce due to the small size of these nanoparticles. $R 1$ sample calcined at $600^{\circ} \mathrm{C}$ in air for $5 \mathrm{~h}$ show increasing crystallinity as a result of phosphate incorporation. The mesostructure of $R 2$, however, collapse at $600^{\circ} \mathrm{C}$ but in case of $R 1$, the mesostructure is found to prevail even at higher temperature as is evident from low angle XRD of $R 1$ (figure $1 \mathrm{~b}$ ).

The surface morphology of phosphated titania is studied by scanning electron microscopy and the micrographs are presented in figures $2 \mathrm{a}$ and $\mathrm{b}$. The sample which appeared are agglomeration of smaller spherical uniform particles. Uniformity in particles implies uniformity in surface treatment. The size of particles of $R 1$ (figure $2 \mathrm{~b}$ ) decreased with phosphate modification and their monodispersity increased.

Average particle size of $R 1$ is $\sim 0.62 \mu \mathrm{m}$ and that of undoped titania $R 2$ is $\sim 1.5 \mu \mathrm{m}$. The average particle size of $R 1$ is smaller than $R 2$ as is evident from the SEM image. The smaller size of $R 1(9.8 \mathrm{~nm})$ in comparison to $R 2(14 \mathrm{~nm})$ is also evident from the average particle size obtained by Scherrer method from XRD. Because of the high-temperature heat treatment, however, aggregates in the micrometer range can be observed in a wide range of particle sizes. No significant difference could be observed in particle morphology: the particles of both $R 1$ and $R 2$ were spherical regardless of their phosphate content.

EDX (figure 3) analysis of phosphated titania samples calcined at $600^{\circ} \mathrm{C}$ showed that the granular aggregates contain phosphorous.

Since our aim was to prepare mesoporous titania with high surface area, TEM image is of great importance as it shows uniform porous structure. A worm-hole like mesostructure without very long range order is clearly visible on the edges of the TEM images of phosphated titania, $R 1$ (figure $4 \mathrm{a}$ ). This structure prevails even after calcination at $600^{\circ} \mathrm{C}$. The mesostructure is completely destroyed at $600^{\circ} \mathrm{C}$ for $R 2$ (figure 4b). The high thermal stability of $R 1$ even at $600^{\circ} \mathrm{C}$ is due to inter-dispersed amorphous titanium phosphate matrix that inhibits the crystalline grain growth of the embedded anatase titania (figure 4c) and provides dissimilar boundaries during calcination.

The thermal behaviour of phosphated titania $R 1$ was investigated using thermogravimetric analyser at temperatures ranging from room temperature to $750^{\circ} \mathrm{C}$ (figure 5). The curve can be divided into three main regions $0-120^{\circ} \mathrm{C}, 120$ $500^{\circ} \mathrm{C}$ and above $500^{\circ} \mathrm{C}$. The first region is attributed to the removal of organic residues and physically adsorbed 
water present in the synthesized materials. This part of the organic residue can be removed by drying at low temperature under vacuum. A very small \% wt. was lost in this region. The second region is attributed to the burnout of any bounded water and chemically bonded organic material. The weight loss over $500^{\circ} \mathrm{C}$ is extremely small and is attributed to the removal of bounded water. According to Bickley and Navio (1985), the loss of adsorbed molecular water in the range is related to the development of porosity.

The pore size distribution and $\mathrm{N}_{2}$ adsorption-desorption isotherms of phosphate titania at $600^{\circ} \mathrm{C}$ is shown in figure 6 . The isotherm is found to be of type IV, which is characteristic of mesoporous materials. It was found that the pore size distribution of $R 2$ is narrower than that of $R 1$. For $R 1$, BET surface area was $28 \mathrm{~m}^{2} / \mathrm{g}$ and for $R 2$ it was $137 \mathrm{~m}^{2} / \mathrm{g}$ (table 1 ). The effect of preparation of in situ with phosphoric acid can be seen in higher surface area obtained in the phosphate sample. Without doubt, the hydrolysis and condensation rates during gelation are modified by phosphoric acid. Under calcination condition, the surface area of $R 1$ is much more than that of undoped titania $R 2$. The low surface area of $R 2$ calcined at $600^{\circ} \mathrm{C}$ confirms complete destruction of the mesoporous structure. Obviously, incorporation of phosphorous can stabilize the framework of mesoporous $\mathrm{TiO}_{2}$.

Figure 7 shows UV-visible diffused reflectance spectra of samples $R 1$ and $R 2$. Both undoped titania $R 2$ and phosphated titania $R 1$ display clear UV absorption. $\mathrm{TiO}_{2}$ nanomaterials show band-to-band absorption at $409 \mathrm{~nm}$. However, phosphated $\mathrm{TiO}_{2}$ nanomaterials $R 1$ exhibit a blue-shifted band-to-band-type absorption at $391 \mathrm{~nm}$. The bandgap of undoped titania $R 2$ is $3.03 \mathrm{eV}$, while for phosphated titania $R 1$ is $3.17 \mathrm{eV}$. The optical absorption edge of the phosphate titania $R 1$ shifted slightly to lower wavelength. This is due to the quantum-size effect because the UV-visible absorption band edge is a strong function of average particle size of titania for diameters $<10 \mathrm{~nm}$ (Brus 1986; Zhang et al 2000). The crystallite sizes decrease after treatment with phosphoric acid, i.e. for pure $\mathrm{TiO}_{2}$ crystallites, it was $\sim 14 \mathrm{~nm}$ whereas for phosphated crystallites, it was $\sim 9.8 \mathrm{~nm}$ as calculated from X-ray diffractograms. This statement is supported
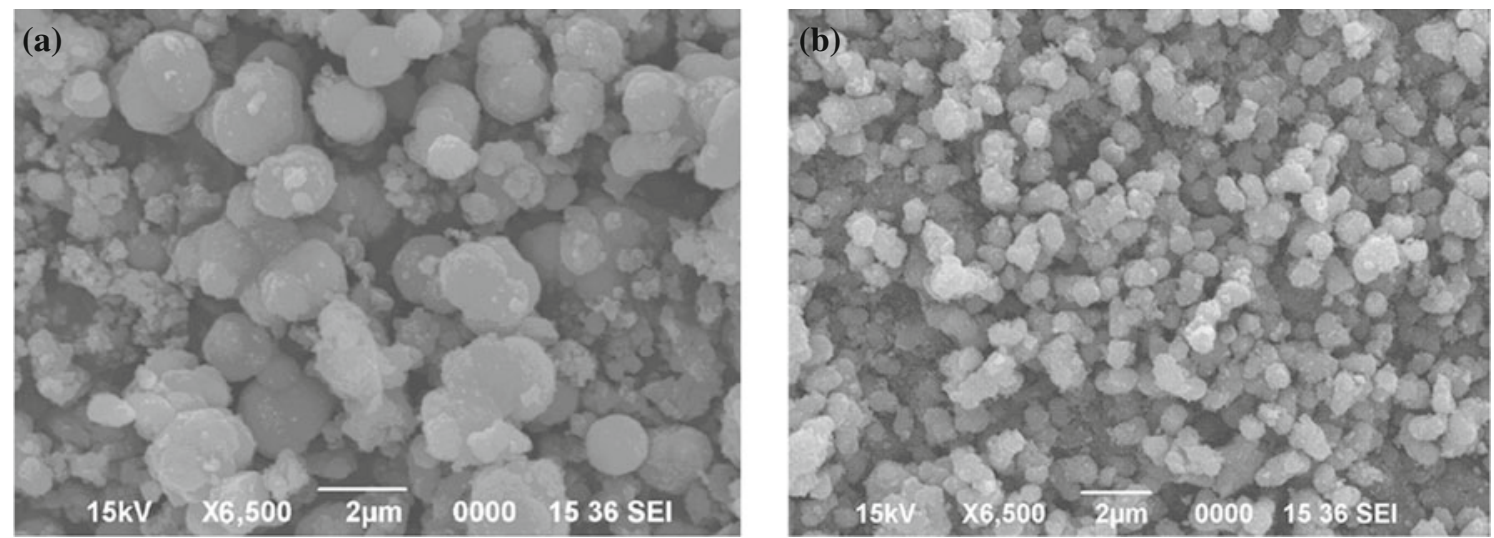

Figure 2. SEM of (a) undoped titania $R 2$ and (b) phosphate titania.

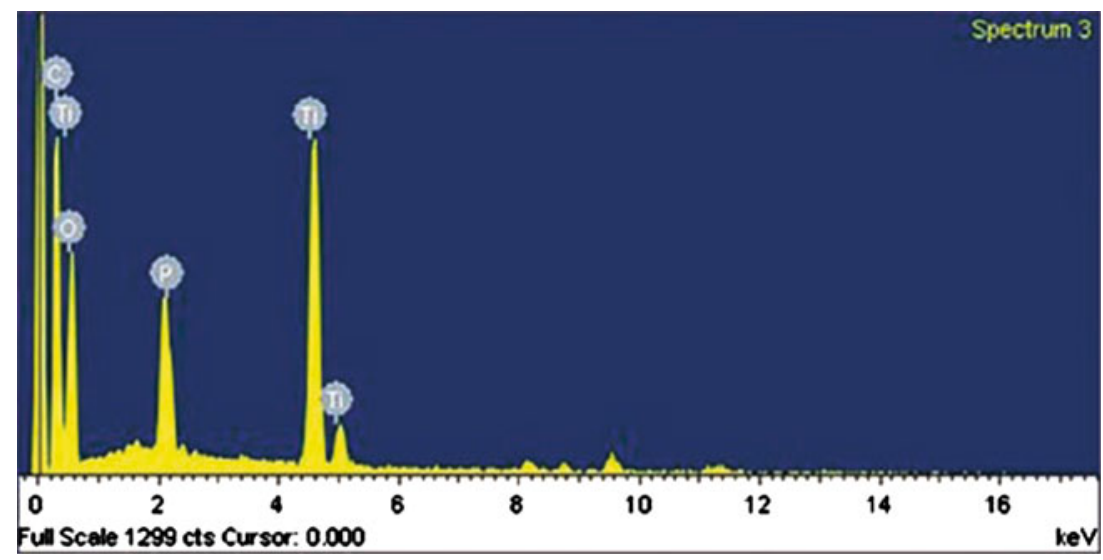

Figure 3. EDX of phosphate titania. 
by SEM micrographs (figures $2 \mathrm{a}$ and $\mathrm{b}$ ) where the size of $R 2$ appears to be larger than $R 1$.

As the chemical composition and structure changes, the vibrational motion in the materials also changes. Thus, the vibrational motions in materials provide information about their chemical composition and structure. Figures $8 \mathrm{a}$ and $\mathrm{b}$ show the evolution of FTIR spectra for undoped titania $R 2$ and phosphated titania $R 1$. Both $R 1$ and $R 2$ displayed high
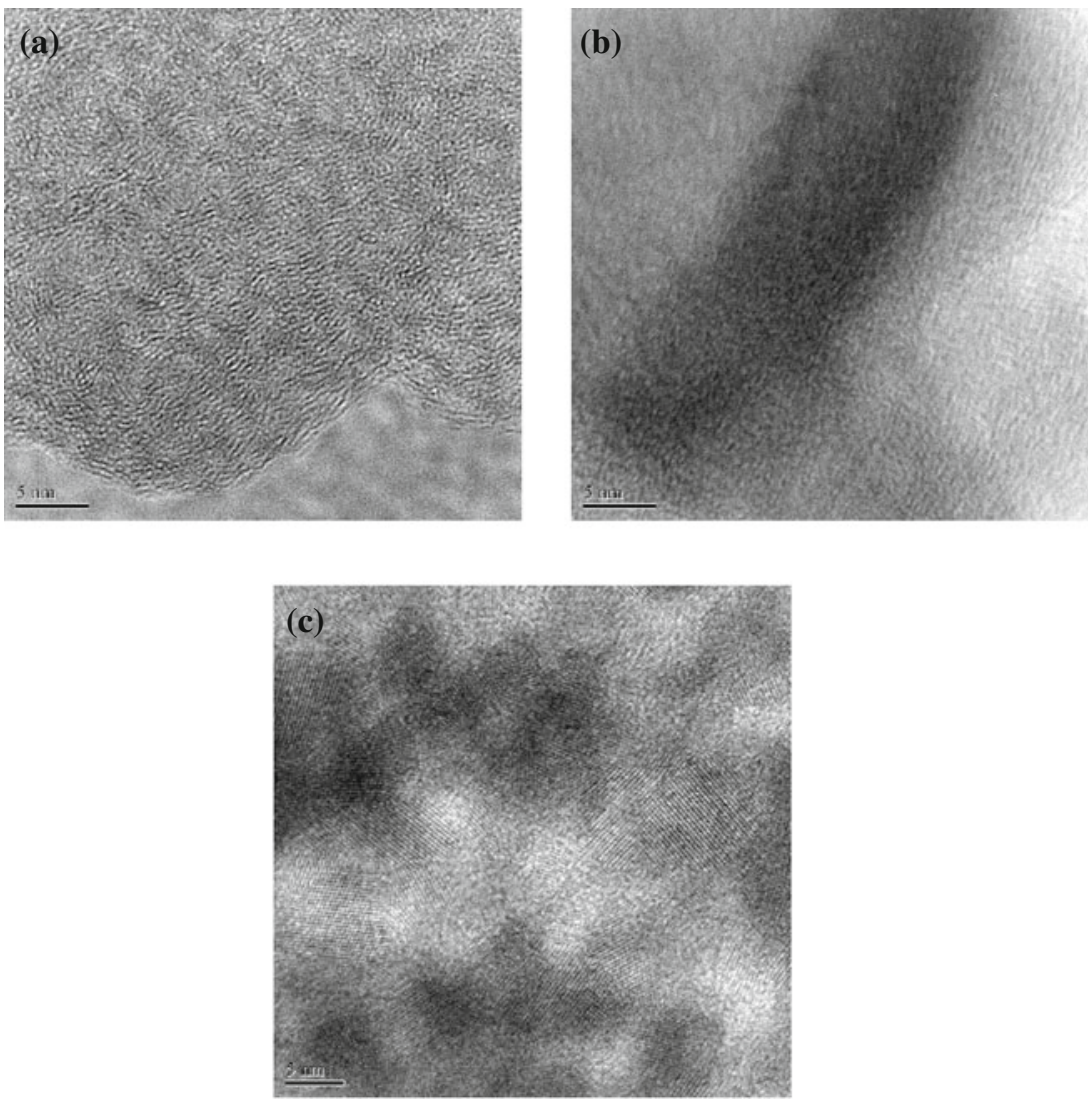

Figure 4. TEM of (a) $R 1$, (b) $R 2$ and (c) crystal boundaries of $R 1$.

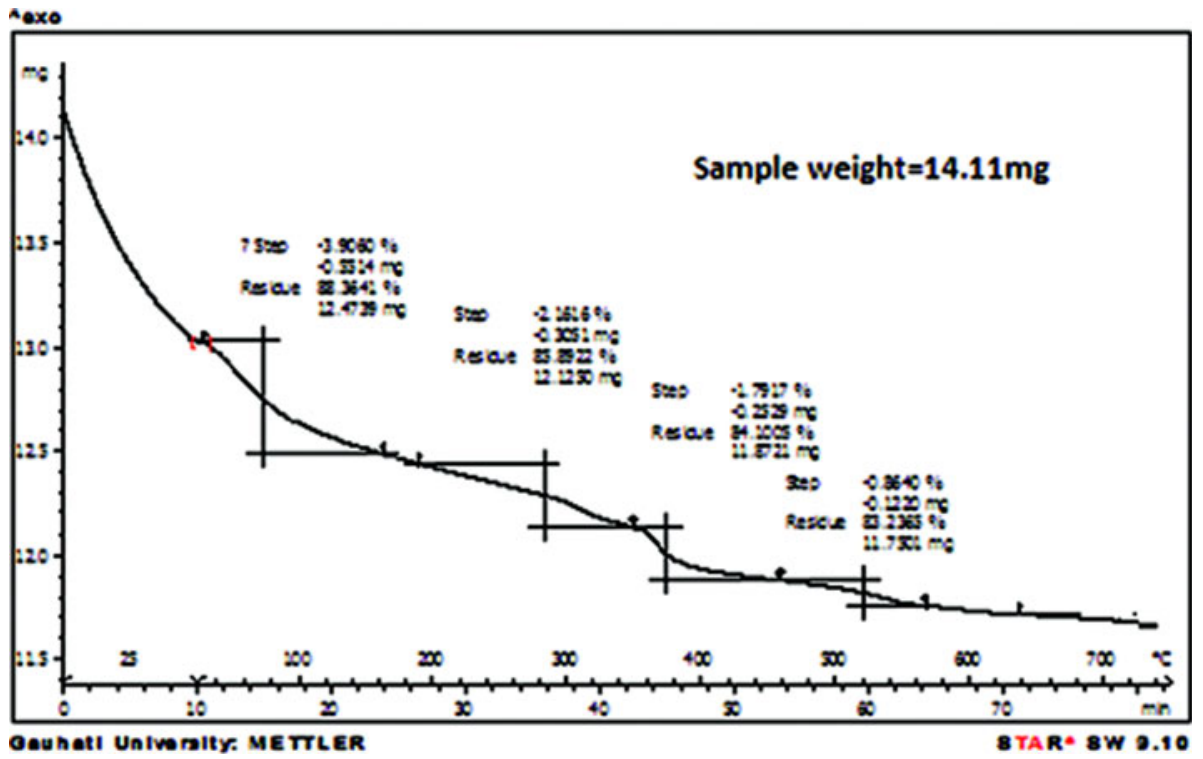

Figure 5. TGA of $R 1$. 
absorbance from $800 \mathrm{~cm}^{-1}$ to $4000 \mathrm{~cm}^{-1}$. The signals in the range $400-1250 \mathrm{~cm}^{-1}$ are characteristic of the formation of a Ti-O-Ti lattice. The IR absorption peak at $830 \mathrm{~cm}^{-1}$ can be attributed to the Ti-O vibrations in anatase phase $\mathrm{TiO}_{2}$ (Sigaev et al 1990). IR absorption at $530 \mathrm{~cm}^{-1}$ can be attributed to the Ti-O vibrations in rutile phase $\mathrm{TiO}_{2}$. Absence of peak at $530 \mathrm{~cm}^{-1}$ confirms that $R 1$ was devoid of rutile phase.

For mesoporous titania (figure 8a), it is believed that the broad peaks at 3416 and $1633 \mathrm{~cm}^{-1}$ correspond to the surface-adsorbed water and hydroxyl groups (Ding et al 2000). For the phosphated titania $R 1$ (figure 6b), peaks at 3402 and $1629 \mathrm{~cm}^{-1}$ are more broad compared to $R 1$ showing that it has more surface-adsorbed water and hydroxyl groups than $R 1$. This can be attributed to the larger surface area of the calcined $R 2$ and presence of Ti ions in a tetrahedral coordination in the calcined $R 2$. Ti ions in a tetrahedral coordination are more effective in adsorbing water (Makarova et al 1995). A broad absorption peak at $963-1288 \mathrm{~cm}^{-1}$ is observed on the IR spectra of $R 1$ but is absent for the calcined $R 2$. The peaks in this range are often characteristic frequencies of $\mathrm{PO}_{4}^{-3}$ (Bhaumik and Inagaki 2001). However, the absence of $\mathrm{P}=\mathrm{O}$ peaks at 1300 $1400 \mathrm{~cm}^{-1}$ does not support that $\mathrm{PO}_{4}^{-3}$ exists as such. Thus FTIR studies as well as EDX result reveal that phosphorous might have been incorporated into the titania matrix. It does not exist as $\mathrm{PO}_{4}^{-3}$ or polyphosphoric acid attached to the $\mathrm{TiO}_{2}$ surface (Jimenez-Jimenez et al 1998). It has also been reported that when triblock copolymer was used as a

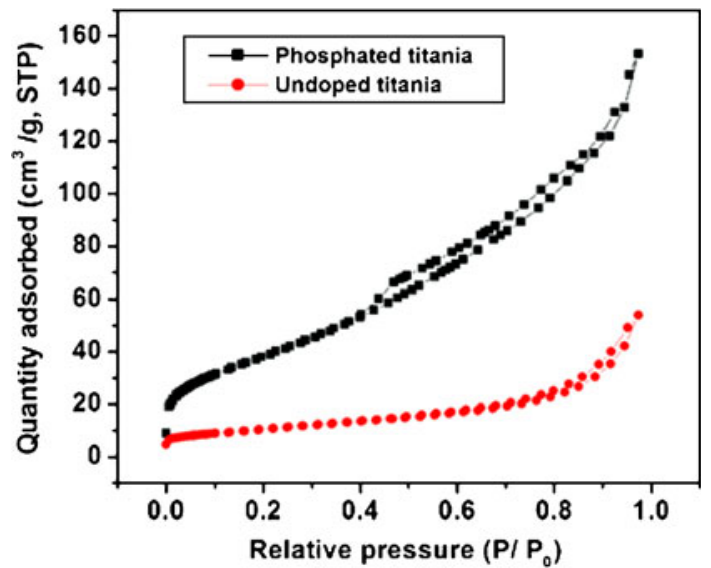

Figure 6. BET surface areas of $R 1$ and $R 2$. structure directing agent, the calcined mesoporous titania exhibited a robust inorganic framework with thick channel wall which consists of amorphous titania with embedded semi-crystalline anatase (Yang et al 1998, 1999). The mesoporous structure of phosphated titania is retained even after calcination at higher temperature giving high surface area. Since the Ti ions in mesoporous titanium phosphate are mainly in a tetrahedral environment, it can be concluded that in our case also the modified phosphated titania $R 1$ contains titanium phosphate (Jones and Hockey 1971).

Variations in FT-IR spectra of ammonia during its thermal desorption from the phosphated titania sample annealed at $600^{\circ} \mathrm{C}$ are shown in figure 9. Ammonia associated with Lewis acid sites was observed in all samples investigated, as evidenced by the peak at $1403 \mathrm{~cm}^{-1}$. However, with increase in temperature, stability of these acid sites decreases. This is confirmed by the transmittance percentage of desorbed ammonia from the samples at different temperatures. This higher surface acidity of the calcined $R 1$ can be attributed to the presence of $\mathrm{Ti}$ ions in a tetrahedral coordination, which can act as Lewis acid sites. These Lewis acid sites can easily adsorb oxygen and water molecules (Suda and Morimoto 1987). The surface area of $R 2$ is very small compared to that of $R 1$. Still some amount of acid site was observed with $R 2$ at $100^{\circ} \mathrm{C}$. But when the temperature was raised to $200^{\circ} \mathrm{C}$, it was found that no acid site was associated with undoped titania $R 2$.

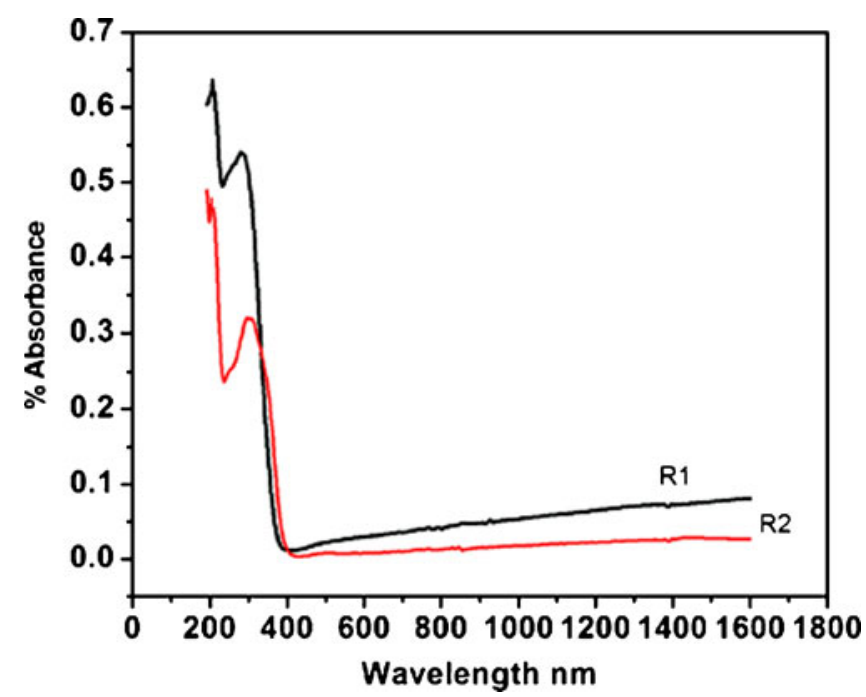

Figure 7. DRS of $R 1$ and $R 2$.

Table 1. BET surface area and pore volumes of $R 1$ and $R 2$.

\begin{tabular}{lccc}
\hline Material & Crystalline size $(\mathrm{nm})$ & Surface area $\left(\mathrm{m}^{2} / \mathrm{g}\right)$ & Pore volume $\left(\mathrm{cm}^{3} / \mathrm{g}\right)$ \\
\hline Mesoporous titania $R 1$ & 17 & 28 & 0.055119 \\
Phosphated titania $R 2$ & 9.8 & 137 & 0.237148 \\
\hline
\end{tabular}



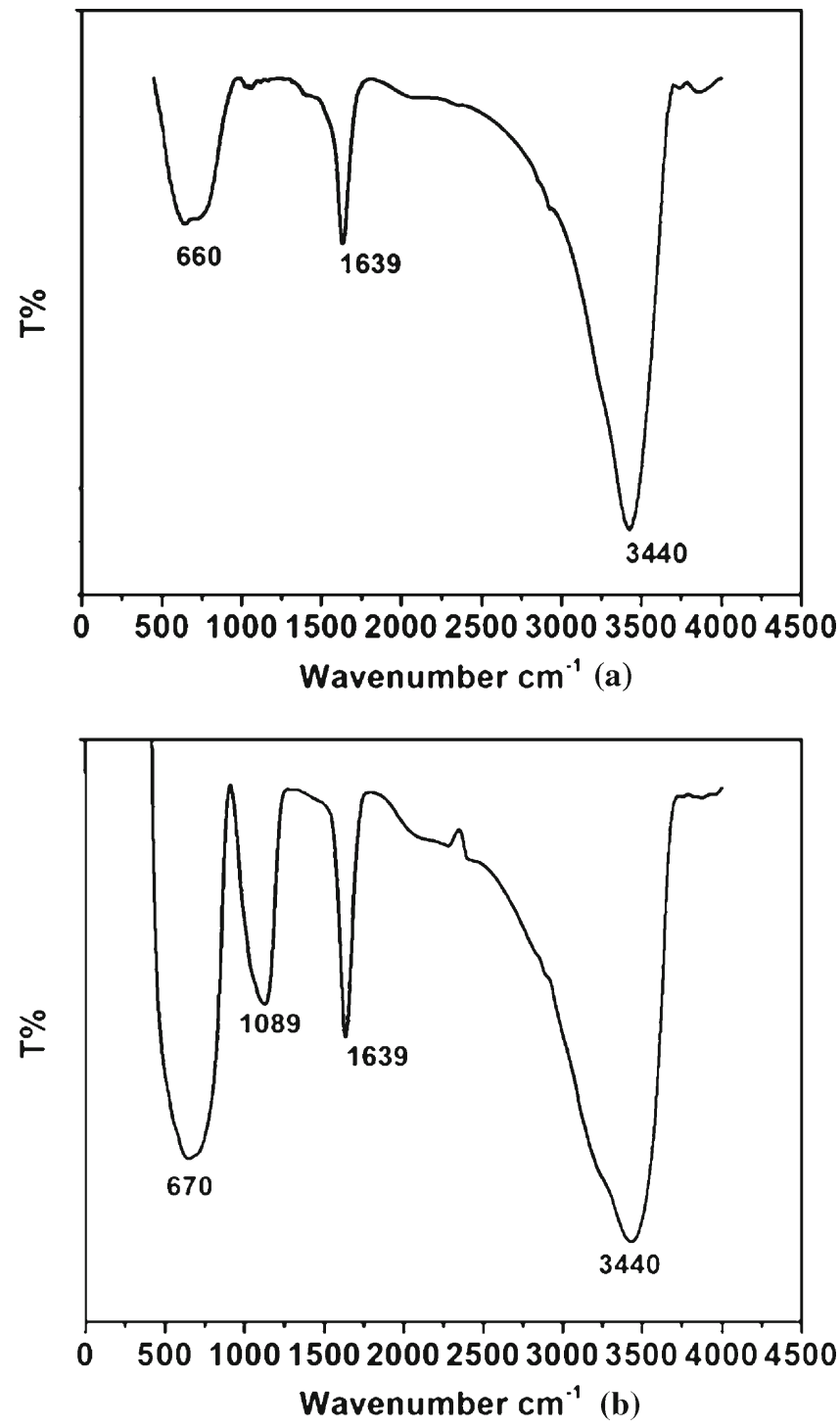

Figure 8. FTIR of (a) $R 2$ and (b) $R 1$.

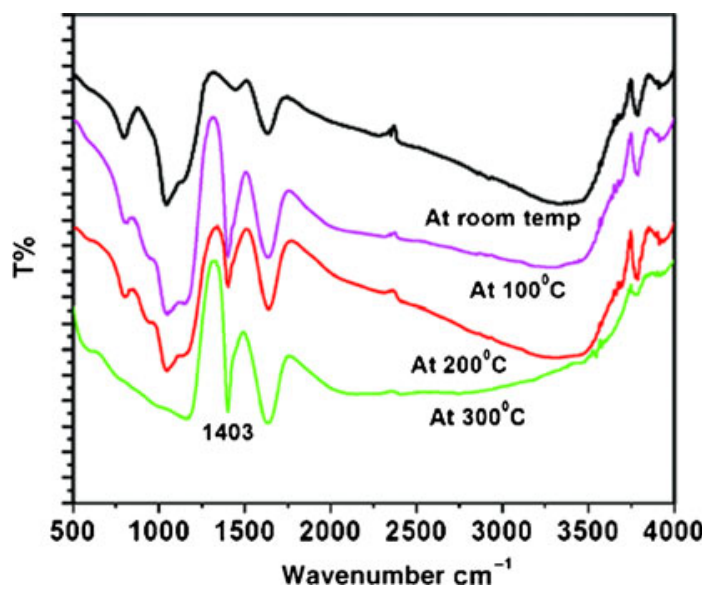

Figure 9. Development of acid sites of $R 1$.

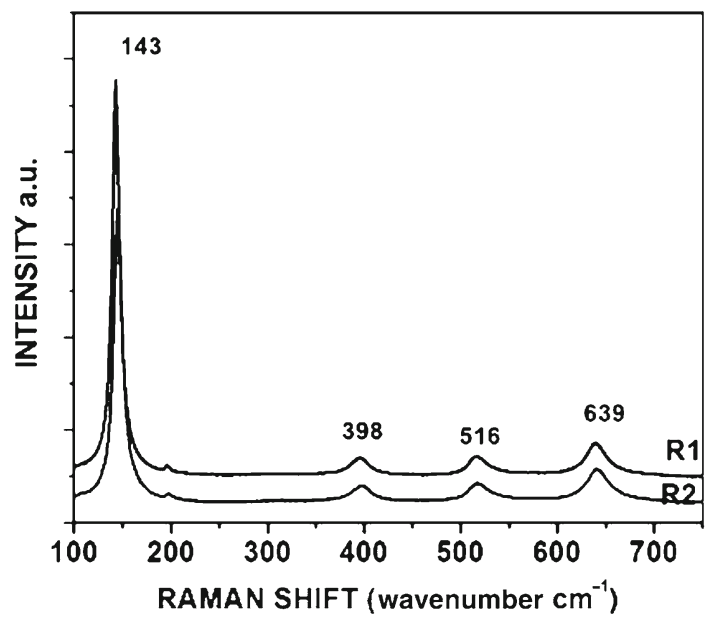

Figure 10. Raman spectra of $R 1$ and $R 2$.

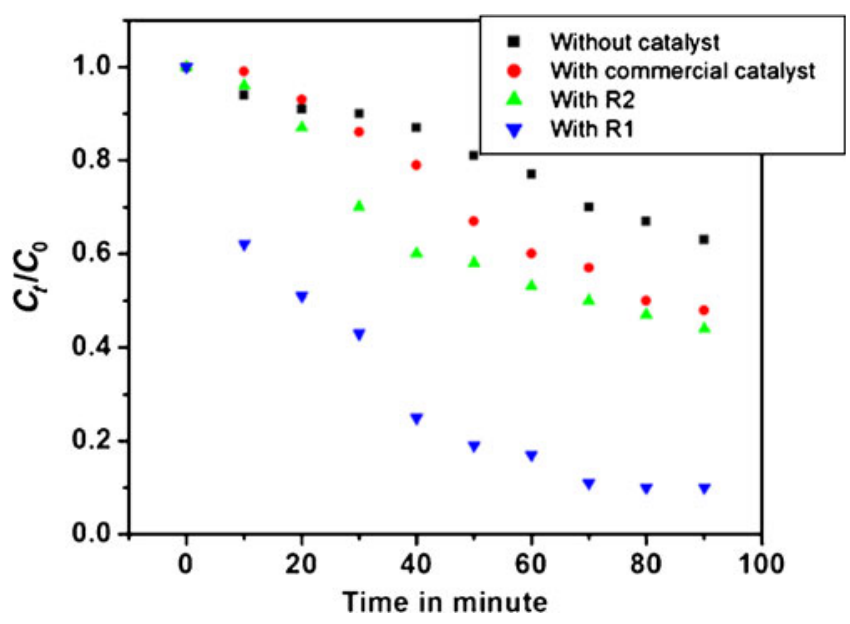

Figure 11. Comparison of photocatalytic properties of $R 1, R 2$ and commercial titania.

As shown in figure 10, the Raman spectrum of the calcined samples also confirmed that $R 1$ and $R 2$ were present in pure anatase phase, corresponding to principal peaks around $\sim 143\left(E_{\mathrm{g}(1)}\right), 197\left(E_{\mathrm{g}(2)}\right), 399\left(B_{\lg (1)}\right), 519\left(A_{\lg }, B_{\lg (2)}\right)$ and $639 \mathrm{~cm}^{-1}\left(E_{\mathrm{g}(3)}\right)$.

\section{Photocatalytic activity of catalysts in aqueous phase degradation of fluoresceine}

The photocatalytic activity of the prepared samples was determined by the degradation of $10^{-5} \mathrm{M}$ fluoresceine dye aqueous solutions under UV radiation (at $500.5 \mathrm{~nm}$ ). In the regions where the Lambert-Beer law is valid, the concentration of fluorescein dye is proportional to absorbance. The time dependence of fluorescein decomposition can be described by the following first order kinetic reaction,

$$
\ln \left(C_{0} / C_{t}\right)=k t,
$$


where $C_{0}$ and $C_{t}$ are the initial concentration and reaction concentration of the dye after time, $t$, respectively $k$ the rate constant. The photocatalytic activity of all catalysts was then evaluated by measuring the absorbance $\left(C_{t}\right)$ of fluorescein UV-visible spectrum at $500.5 \mathrm{~nm}$ during every 10 min interval. With the assumption that Beer's law was obeyed, the graph of absorbance against $t$ is equivalent to the graph of concentration against $t$ and the latter was plotted as shown in figure 11. The rate of degradation of the chromophore of the dye can thus be determined from the concentration vs time plots. Phosphate modified sample $R 1$ showed higher photocatalytic activities than that of pure $\mathrm{TiO}_{2}$ and of commercial $\mathrm{TiO}_{2}$. Phosphate modification leads to reduction of particle size. Again the high photocatalytic activity of $R 1$ can be explained by the bandgap as well as the coordination of $\mathrm{Ti}$ ions. It is commonly accepted that a larger bandgap corresponds to powerful redox ability (Lin et al 1999). The oxidative degradation of fluorescein by $\mathrm{TiO}_{2}$ is believed to be initiated by $\mathrm{OH}$ radicals. In presence of $\mathrm{O}_{2}$, the $\mathrm{OH}$ radicals are formed according to the following reactions (Yamashita et al 1998).

$$
\begin{aligned}
& \mathrm{TiO}_{2} \rightarrow h^{+}+e^{-}, \\
& e^{-}+\mathrm{O}_{2} \rightarrow \mathrm{O}_{2}^{-}, \\
& \mathrm{O}_{2}^{-}+2 \mathrm{H}^{+}+e^{-} \rightarrow \mathrm{H}_{2} \mathrm{O}_{2}, \\
& \mathrm{H}_{2} \mathrm{O}_{2}+\mathrm{O}_{2} \rightarrow \mathrm{OH}^{0}+\mathrm{OH}^{-}+\mathrm{O}_{2}, \\
& \mathrm{H}^{+}+\mathrm{H}_{2} \mathrm{O} \rightarrow \mathrm{OH}^{0}+\mathrm{H}^{+} .
\end{aligned}
$$

Further the mesoporous nature of the material results in the increase of surface area. More the surface area more will be production of hydroxyl radicals and hence more will be photocatalytic decomposition. These combined effects make the substrate adsorption stronger. It is clear from figure 10 that in $R 1$ with higher surface area and smaller particle size, photocatalytic activity was better. Both $R 1$ and $R 2$ showed higher photocatalytic activities than commercial titania.

\section{Conclusions}

A nanocrystalline phosphate doped $\mathrm{TiO}_{2}$ has been synthesized by a simple hydrothermal method involving titanium isopropoxide, phosphoric acid and block polymer. The incorporation of phosphate ions stabilizes the titania in the anatase phase and Lewis acid sites were developed. Phosphate modification caused a marked change in the $\mathrm{TiO}_{2}$ particle size as well as surface area thereby increasing photocatalytic activity. Phosphate is not adsorbed simply in the surface of titania but exists as $\mathrm{TiPO}_{4}$ and surrounds anatase crystallites in such a way so that no crystal growth occurs at high temperatures due to quantum growth effect. Since no XRD peak of $\mathrm{TiPO}_{4}$ is observed, hence we conclude that it is amorphous in nature. Photocatalytic activity of phosphated titania is much more than that of undoped titania due to higher surface area.

\section{References}

Armstrong G, Armstrong A R, Canalcs J and Bruce P G 2005 Chem. Commun. 192454

Bhaumik A and Inagaki S 2001 J. Am. Chem. Soc. 123691

Bickley R I and Navio J A 1985 Photocatalytic production of energy-rich compounds (eds) G Grassi and D O Hall (London: Elsevier) p 297

Brus L 1986 J. Phys. Chem. 902555

Chen H R, Shi J I, Hua Z I, Ruan M I and Yan D S 2001 Mater. Lett. 51187

Clesla U, Schacht S, Stucky G D, Unger K K and Schuth F 1996 Angew Chem. Int. Ed. Engl. 35541

Colón G, Sánchez-Espana J M, Hidalgo M C and Navío J A 2006 J. Photochem. Photobiol. A20 179

Ding Z, Lu G Q and Greenfield P F 2000 J. Phys. Chem. B104 4815

Hino M and Arata K 1980 J. Chem. Commun. 851963

Huang L and Li Q Z 1999 Chem. Lett. 82928

Jimenez-Jimenez J, Mairles-Torres P, Olivera-Pastor P, RodriguezCastellon E, Jimenez-Lopez A, Jones D J and Roziere J 1998 J. Adv. Mater. 10812

Jones P and Hockey J A 1971 Trans. Faraday Soc. 672679

Larsen G, Loreto F, Nasity M, Petkovu L M and Shobe D S 1996 J. Catal. 164246

Lin J, Yu J C, Lo D and Lam S K 1999 J. Catal. 183368

Makarova O V, Dakka J, Shedon R A and Tsyganenko A A 1995 Stud. Surf. Sci. Catal. 94163

Regan B O and Gratzel M 1999 Nature 3537371

Sigaev V N, Pernice P, Aronne A, Akimova O V, Stefanovich S Y and Scaglione A 1990 J. Non-Cryst. Solids 126202

Suda Y and Morimoto T 1987 Langmuir 3786

Yamashita H, Honda M, Harada M, Ichihashi Y, Anpo M, Hirao T, Itoh N and Iwamoto N 1998 J. Phys. Chem. B102 10707

Yang P D, Zhao D Y, Margolesce D I, Chmelka B F and Stucky G D 1998 Nature 396152

Yang P D, Zhao D Y, Margolesce D I, Chmelka B F and Stucky G D 1999 Chem. Mater. 112813

Yu J C, Zhang L, Zheng Z and Zhao J 2003 Chem. Mater. 152280

Zhang Q H, Gao L and Guo J H 2000 Appl. Catal. B26 207 